\title{
Development of a New and Simple Postoperative Pain Fear Scale for Elective Surgeries in Adult Patients
}

\author{
๑ Seher Unver, ๑ Fatma Nesrin Turan* \\ Trakya University Faculty of Health Sciences, Department of Surgical Nursing, Edirne, Turkey \\ *Trakya University Faculty of Medicine, Department of Biostatistics and Informatics, Edirne, Turkey
}

\begin{abstract}
Aim: There is a need to assess the pain fear levels of surgical patients simply and appropriately before the surgery. This study aimed to develop and test the psychometrics of an instrument to evaluate the fear of postoperative pain.

Methods: This methodological study was conducted at four surgical clinics including general surgery, orthopedics and traumatology, neurosurgery, heart and vessel surgery of a university hospital between 28 March and 19 October 2018. Totally, 150 patients who were scheduled for elective surgery and at their preoperative day were included. This scale contained 10 items related to the postoperative pain sources and aimed to identify the pain fear of patients preoperatively. To measure the sampling adequacy, Kaiser-Meyer-Olkin index and Bartlett's test of sphericity was used. Explanatory and confirmatory factor analyses were conducted to evaluate the construct validity. The internal consistency of the scale was evaluated by Cronbach's alpha calculation. All hypotheses were tested in two directions.
\end{abstract}

Results: The total variance explained $55.5 \%$ of the variance for one factor structure consisting of 10 items. The model fit index values through the confirmatory factor analysis were found to support this structure.

Conclusion: The scale is appropriate to be used in clinical settings to quickly evaluate the elective surgical patients' fear level of postoperative pain preoperatively.

Keywords: Postoperative pain fear scale, postoperative pain, scale development, surgical patient, Turkish

\section{Introduction}

Fear is defined as an emotional response to traumatic events such as surgical interventions $(1,2)$. Patients waiting for an upcoming surgery may describe the fear and this may be related to many conditions $(3,4)$. In the previous studies, fear of anesthesia, surgical procedure and unknown were reported as the factors of surgical fear $(5,6)$. Many studies have found that surgical fear is related to fear of postoperative pain and reported that preoperative predictors of postoperative pain, fear were associated with postoperative pain $(4,7)$.

Pain-related fear is identified to be an important target of pain treatment and with reducing pain fear, improvement in the pain management outcomes is evidenced to be possible (8). Fear-avoidance beliefs are evidenced to play a significant role in pain experience, and psychological wellbeing, so that assessing the fear beliefs with standardized instruments is recommended for the first step of patients who present with a pain condition $(9,10)$. Clinical nurses and physicians are the primary professionals in taking care of patients and evaluating their pain levels. Screening patients preoperatively to identify their pain fear helps to reduce unwanted pain expectations and increase the pain coping abilities of patients $(11,12)$.

Fear of pain is possible to be measured with some assessment tools including the Fear of Pain Questionnaire III (13), Parent Fear of Pain Questionnaire (14) and Pain Catastrophizing scale (15). However, they are not specific for surgical pain fear, complex and not practical to be used at the busy surgical clinics for preoperative evaluation. Therefore, there is a need for a simple, timesaving and appropriate tool to assess pain fear levels at the clinic preoperatively or before transferring to the operating room.

Address for Correspondence: Seher Unver, Trakya University Faculty of Health Sciences, Department of Surgical Nursing, Edirne, Turkey Phone: +90 5055007217 E-mail: seher.unver@hotmail.com ORCID: orcid.org/ 0000-0003-1320-1437 Received: 28.03.2021 Accepted: 30.04.2021 
Preoperative investigation of postoperative pain fear among surgical patients for planning an effective pain management regimen is essential. Knowing the predictors of postoperative pain may be helpful for making decisions about optimal pain management techniques. Unfortunately, there is not any tool to evaluate surgical pain fear. The development of this will fill the gap in the literature and help health professionals to evaluate the fear of postoperative pain before surgical interventions of the patients. With the evaluation of the pain fear levels of the surgical patients, it is intended to decrease the postoperative pain and anxiety by providing interventions on patient care and medical treatments. The purpose of this study was to develop and test the psychometrics of an instrument to evaluate the fear of postoperative pain.

\section{Methods}

\section{Ethical Considerations}

This study was approved by the ethical review board of the University Ethics Committee of the Trakya University Medical Faculty (date: 19.02.2018 decision number: $03 / 24$ ) and permission to conduct the study was obtained from the hospital directory. Before the interviews start, the aim and context of the study was explained to the patients and they were asked to sign an informed consent form if they are volunteered.

\section{Research Design and Sample}

The study was designed as a methodological study and included the development and validation of the postoperative pain fear scale. The study took place at the four common surgical clinics (general surgery, orthopedics and traumatology, neurosurgery and heart and vessel surgery) at a university hospital in Turkey between 28.03.2018-19.10.2018 with 150 patients. While the reliability and validity studies require a sample size at least 5-10 times of the total number of scale items, the sample size is calculated as 150, fifteen times the 10 items of the present study (16). Inclusion criteria were being voluntary, scheduled for elective surgery, being at the preoperative day, able to communicate in Turkish, had no mental problem.

\section{Data Collection}

For data collection, a data collection form with third parts is used. In the first part, questions about age, gender, clinic and previous surgery history were included; in the second part, the Postoperative Pain Fear scale (POPFS), was included to develop within this research; in the third part, the Surgical Fear Questionnaire (SFQ) and Fear of Pain Questionnaire-III (FPQ-III) were included to evaluate criterion validity.
The SFQ was developed by Theunissen et al. (4) in 2014 and the Turkish adaptation was conducted by Bagdigen and Ozlu (17) in 2018. It consists of 8 items based on an 11-point Likert type scored 0 "I have no fear at all" to 10 "I have a very great fear". It has two sub-scales. Items 1 to 4 assess the source of fear caused by short-term results of the surgery and items 5 to 8 assess long-term results. The higher scale score indicates a higher level of surgical fear. Cronbach's alpha internal consistency coefficient was found as 0.95 in the Turkish version (17).

The FPQ-III was developed by McNeil and Rainwater (13) in 1998 and the Turkish adaptation was conducted by Unver and Turan (18) in 2018. It consists of 30 items based on a 5-point Likert type scored 1 "not at all" to 5 "extreme". It has three sub-scales. Items $1,3,5,6,9,10,13,18,25,27$ assess the severe pain fear, items $2,4,7,12,19,22,23,24,28,30$ assess the minor pain fear and items $8,11,14,15,16,17,20,21,26,29$ assess the medical pain fear. The higher scale score indicates the higher fear. Cronbach's alpha internal consistency coefficient was found as 0.92 in the Turkish version (18). In this study, the cross-validation of this scale was also completed, and the results supported that this scale is valid, reliable and can be used in surgical patients.

The data collection form was administered to the patients in their rooms at the clinic before their surgery via face-to-face interviews by the same researcher. It took approximately 10 to 15 minutes to complete.

\section{Scale Development}

The scale development was completed following three steps. The first step included item generation. In this step, a pool of items was prepared by a literature review to shape the draft of the scale. Within the context, the studies conducted national and international were examined in terms of postoperative pain and fear, and the expressions that could be used in the scale were determined $(3,4,17,19)$. It was noted that these expressions were related to the fear experienced by the patients who were planned to undergo surgery. It was also aimed that each of the items will be directed towards the fear of pain that are easy to be understood by patients. Totally 13 items were identified which specifically focus on the postoperative pain sources (such as wound-related pain, suture related pain, moving related pain, dressing changing related pain, deep breathing-related pain, coughing related pain, getting out of bed-related pain, feeding-related pain, urinary drain related pain, nasogastric drain related pain, intra-abdominal gas-related pain, medical treatmentrelated pain).

The second step included the expert consultation. In this step, draft scale items were sent to the experts via e-mail to evaluate their opinions. Ten experts in the field of 
anesthesiology (1 medical doctor), psychology nursing (1 academician), surgery (4 academicians - working at general surgery service), surgeon (2 medical doctors), surgical nursing ( 2 academicians). They were asked to control if the scale items related to the fear of pain after surgery, to express their opinions about each item, to check the items according to grammar and word suitability, cultural compatibility, clear to understand and a need for another item to add.

The third step included the psychometric tests. In this step, psychometric tests of the 10 items were conducted to evaluate the validation of POPFS.

\section{Statistical Analysis}

In the analysis of data, the package program IBM Corp. Released 2010 (IBM SPSS Statistics for Windows, Version 22.0. Armonk, NY: IBM Corp.) was used. To evaluate the data distribution, Shapiro-Wilk test was used. Arithmetic mean \pm standard deviation, median (minimum-maximum) values were given as descriptive statistics. Correlation between nonparametric variables was determined by the correlation coefficient of Spearman rho.

To measure the sampling adequacy, Kaiser-Meyer-Olkin (KMO) index and Bartlett's test of sphericity was used. Principal component analysis (PCA) was assessed for the construct validity and confirmatory factor analysis (CFA) was used to confirm the factor structure. For confirmatory factor analysis, LISREL 9.30 for Windows (Scientific Software International, Inc.) was used. In calculating the scope validity ratio, the content validity ratio (CVR) formula that was developed by Lawshe (20) to calculate how much each item was required was used. The internal consistency (reliability) of the scale was evaluated by Cronbach's alpha calculation. $p<0.05$ was considered statistically significant and all hypotheses were tested in two directions.

\section{Results}

\section{Sample Characteristics}

The mean age of the patients was $54.13 \pm 16.36$ years and $51.3 \%$ of them were male. The percentage of the patients that will have a surgery at general surgery clinic was $45.3 \%$ and $72 \%$ of them had previous surgery history. The demographic characteristics are shown in Table 1.

\section{Cross-Validation of FPQ-III}

The cross-validation of this scale was completed with the 150 patients waiting for surgery analyzed using the Cronbach's alpha reliability coefficient, KMO measure of sampling adequacy and Bartlett's test of sphericity. As a result of the analysis, the total variance was found as $58.21 \%$ for three-factor structure. According to the explanatory factor analysis (EFA) test, the KMO sampling adequacy was found as 0.918 and Bartlett's test score

\begin{tabular}{|l|l|}
\hline \multicolumn{2}{|l|}{ Table 1. Demographic characteristics of the patients (N=150) } \\
\hline Demographic Characteristics & Value \\
\hline Age (years) (mean \pm SD) & $54.13 \pm 16.36$ \\
\hline Gender (n) & $73(48.7 \%)$ \\
\hline $\begin{array}{l}\text { Female } \\
\text { Male }\end{array}$ & $77(51.3 \%)$ \\
\hline Clinic (n) & $68(45.3 \%)$ \\
\hline $\begin{array}{l}\text { General surgery } \\
\text { Orthopedics and traumatology } \\
\text { Neurosurgery } \\
\text { Heart and vessel surgery }\end{array}$ & $25(16.7 \%)$ \\
\hline Previous surgery history (n) & $25(16.7 \%)$ \\
\hline Yes & $108(72 \%)$ \\
No & $42(28 \%)$ \\
\hline SD: Standard deviation & \\
\hline
\end{tabular}

\begin{tabular}{|c|c|c|c|c|}
\hline POPFS Items & Appropriate & $\begin{array}{l}\text { Quite } \\
\text { appropriate }\end{array}$ & Inappropriate & $\begin{array}{l}\text { Total } \\
\text { expert } \\
\text { number }\end{array}$ \\
\hline POPFS Item 1 & 10 & 0 & 0 & 10 \\
\hline POPFS Item 2 & 10 & 0 & 0 & 10 \\
\hline POPFS Item 3 & 10 & 0 & 0 & 10 \\
\hline POPFS Item 4 & 10 & 0 & 0 & 10 \\
\hline POPFS Item 5 & 10 & 0 & 0 & 10 \\
\hline POPFS Item 6 & 9 & 1 & 0 & 10 \\
\hline POPFS Item 7 & 10 & 0 & 0 & 10 \\
\hline POPFS Item 8 & 8 & 2 & 0 & 10 \\
\hline POPFS Item 9 & 8 & 2 & 0 & 10 \\
\hline $\begin{array}{l}\text { POPFS Item } \\
10\end{array}$ & 10 & 0 & 0 & 10 \\
\hline
\end{tabular}

was found as $\chi^{2}=3210,226, p<0.001$. The factor loads of the scale ranged between 0.352-0.876. The Cronbach's alpha coefficient for the total scale was 0.955 , and 0.938 for the severe pain fear subscale, 0.895 for the minor pain fear subscale, 0.889 for the medical pain fear subscale.

\section{Scale Development}

Draft scale form with 13 items was formed by gathering the determined items according to the expressions. Selected items were about fear of pain-related to wound, sutures, walking, breathing, coughing, feeding, intestinal gas, the tubes and drains. Numeric rating was used from 0-2 $(0=$ no fear, $1=a$ little fear, $2=$ so much fear $)$ for each item. According to the experts' comments and opinions, two items about pain while walking and getting out of bed were picked up in one item; two items about painrelated with tubes in the stomach and urinary were picked up in one item; two items about pain-related sutures and 
wound were picked up in one item and the numeric rating was changed from 0-2 to 0-10 and all items were scored ranging from 0 (not at all afraid) to 10 (very afraid) on a Numeric Rating scale. After completing these changes, opinions of experts were derived from to the same experts for the second time to conduct the content validity. The responses of the experts are shown in Table 2 .

Before the content validity, the relationship between the scale items and the total scale was evaluated. The correlation coefficients between the POPFS total score and all the items that make up the scale ranged from 0.691 to 0.869 and were strongly and statistically significant (Table 3).

After the responses of the experts, content validity ratios (CVR) were calculated for each item and as a result, the items of the scale were 10 . The content validity index $(\mathrm{CVI})$ value was calculated as well and as a result, for each item it was found as +1.00 .

\section{Validity}

To evaluate the construct validity of the scale, the KMO test was used to analyze the sample size sufficiency for the EFA. The calculated KMO for 150 samples was found as 0.88 . Bartlett's test was applied for the suitability of the data set and it was found significant $\left(\chi^{2}=807.616\right.$, $p<0.000)$. A PCA was used and as a result, the significant factor loadings of each item were found 0.45 or greater. Table 4 showed the communalities from the single factor analysis.

\begin{tabular}{|l|l|l|}
\hline \multicolumn{3}{|l|}{ Table 3. Scale total score and correlation between scale items } \\
\hline & \multicolumn{2}{|l|}{$\begin{array}{l}\text { Total scale } \\
\text { score }\end{array}$} \\
\hline POPFS Items & r & p \\
\hline $\begin{array}{l}\text { POPFS Item 1. I am afraid that I will have pain due } \\
\text { to wounds and sutures in the operation area. }\end{array}$ & 0.790 & 0.000 \\
\hline $\begin{array}{l}\text { POPFS Item 2. I am afraid that I will have pain } \\
\text { during dressing change. }\end{array}$ & 0.725 & 0.000 \\
\hline $\begin{array}{l}\text { POPFS Item 3. I am afraid that I will have pain when } \\
\text { getting out of bed and walking. }\end{array}$ & 0.691 & 0.000 \\
\hline $\begin{array}{l}\text { POPFS Item 4. I am afraid that I will have pain while } \\
\text { breathing deeply. }\end{array}$ & 0.755 & 0.000 \\
\hline $\begin{array}{l}\text { POPFS Item 5. I am afraid that I will have pain when } \\
\text { COughing. }\end{array}$ & 0.869 & 0.000 \\
\hline $\begin{array}{l}\text { POPFS Item 6. I am afraid that I will have pain while } \\
\text { eating meal. }\end{array}$ & 0.722 & 0.000 \\
\hline $\begin{array}{l}\text { POPFS Item 7. I am afraid that I will have pain due } \\
\text { to a stomach/urinary catheter. }\end{array}$ & 0.755 & 0.000 \\
\hline $\begin{array}{l}\text { POPFS Item 8. I am afraid that I will have pain due } \\
\text { to drains/inserted tubes. }\end{array}$ & 0.809 & 0.000 \\
\hline $\begin{array}{l}\text { POPFS Item 9. I am afraid that I will have pain due } \\
\text { to gas in my intestines. }\end{array}$ & 0.694 & 0.000 \\
\hline $\begin{array}{l}\text { POPFS Item 10. I am afraid that I will have pain } \\
\text { during medication (intramuscular, intravenous). }\end{array}$ & 0.700 & 0.000 \\
\hline $\begin{array}{l}\text { The Spearman rho test. The correlation coefficients between the total score } \\
\text { and all the items were found to be strongly and statistically significant. POPFS: } \\
\text { Postoperative pain fear scale }\end{array}$ \\
\hline
\end{tabular}

\begin{tabular}{|c|c|c|}
\hline \multicolumn{3}{|l|}{ Communalities } \\
\hline POPFS Items & Initial & Extraction \\
\hline POPFS Item 1 & 1.000 & 0.608 \\
\hline POPFS Item 2 & 1.000 & 0.555 \\
\hline POPFS Item 3 & 1.000 & 0.471 \\
\hline POPFS Item 4 & 1.000 & 0.582 \\
\hline POPFS Item 5 & 1.000 & 0.730 \\
\hline POPFS Item 6 & 1.000 & 0.522 \\
\hline POPFS Item 7 & 1.000 & 0.508 \\
\hline POPFS Item 8 & 1.000 & 0.626 \\
\hline POPFS Item 9 & 1.000 & 0.450 \\
\hline POPFS Item 10 & 1.000 & 0.477 \\
\hline
\end{tabular}

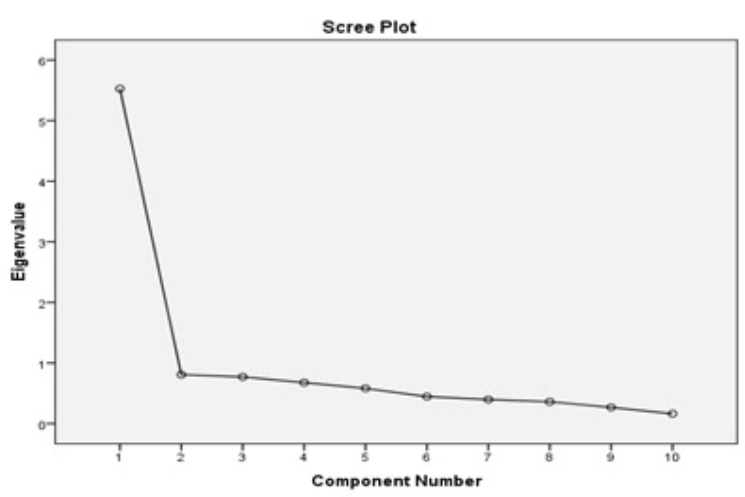

Figure 1. The scree plot (exploratory factor analysis)

After evaluating the sample size sufficiency, EFA was conducted to evaluate the construct validity. The total variance explained $55.5 \%$ of the variance for one factor. The one-factor structure was also confirmed by the scree plot (Figure 1).

After the EFA was performed, CFA was used to check if the model defined by EFA was working in a new sample. According to the model fit indexes, the chi-square/df ratio (3.15), and goodness of fit indexes [Root Mean-Square Error of Approximation (RMSEA) $=0.120$, Standardized Root Mean-Square Residual=0.050, Comparative Fit index $(C F I)=0.907]$ showed that the model of the scale was fit with the data and POPFS was able to be used (Figure 2 and Table 5).

The structural elements (standardized factor loads, t-values, and R2) of the model were examined to fit the indexes. The R2 values ranged between $0.40 \%$ and $0.73 \%$ indicating that the variability in the scale model was mostly explained by POPFS item 5, while the rarely explained POPFS item 10 (Table 6). The mean score of the 


\section{Table 5. The goodness of fit statistics of the model ${ }^{*}$}

\begin{tabular}{|l|l|l|l|}
\hline Statistics & Value & Recommended value & Fitness \\
\hline $\mathrm{X}^{2} / \mathrm{df}$ & 3.15 & $2 \leq \mathrm{X}^{2} / \mathrm{df} \leq 3$ & Marginal fit \\
\hline RMSEA & 0.120 & $0.05 \leq \mathrm{RMSEA} \leq 0.08$ & Marginal fit \\
\hline $\mathrm{Cl}$ & $0.09-0.14$ & close to RMSEA & Marginal fit \\
\hline SRMR & 0.050 & $0.05 \leq \mathrm{SRMR} \leq 0.10$ & Good fit \\
\hline $\mathrm{NFI}$ & 0.871 & $0.90 \leq \mathrm{NFI} \leq 0.95$ & Marginal fit \\
\hline $\mathrm{NNFI}$ & 0.881 & $0.95 \leq \mathrm{NNFI} \leq 0.97$ & Marginal fit \\
\hline $\mathrm{CFI}$ & 0.907 & $0.95 \leq \mathrm{CFI} \leq 0.97$ & Marginal fit \\
\hline GFI & 0.884 & $0.90 \leq \mathrm{GFI} \leq 0.95$ & Marginal fit \\
\hline AGFI & 0.817 & $0.85 \leq \mathrm{AGFI} \leq 0.90$ & Marginal fit \\
\hline
\end{tabular}

* Measures of goodness of fit (Schermelleh-Engel, Moosbrugger and Müller, 2003), RMSEA: root mean-square error of approximation, Cl: Confidence interval, SRMR: Standardized root mean-square residual, NFI: Normed fit index, NNFI: Non-normed fit index, CFI: Comparative fit index, GFI: Goodness of-fit index, AGFl: Adjusted goodness-of-fit index Confirmatory, Factor Analysis showed the model was fit and the scale was able to be used.

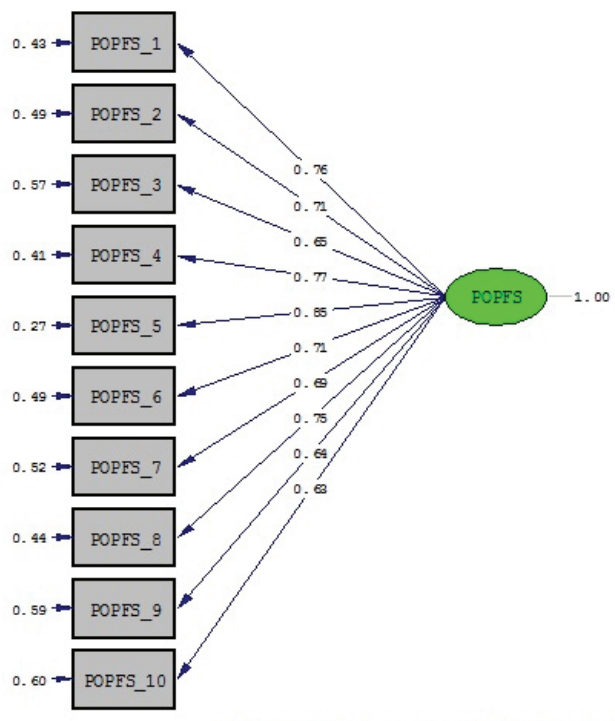

Chi-8quare $=110.40, d f=35, P-v a l u e=0.00000$, RMgEA $=0.120$

Figure 2. Path diagram of the postoperative pain fear scale POPFS: Postoperative Pain Fear scale, RMSEA: Root Mean-Square Error of Approximation

items was $3.24 \pm 2.37$ for total scale items (Table 7 ). To measure the reliability, internal consistency was concerned and Cronbach's alpha for the 10-item postoperative pain scale was found as 0.91 .

\section{Discussion}

Surgical pain is unavoidable in surgery patients and fear is an expected response to pain. Healthcare professionals should be aware of patients' pain fear to reduce such fear and implement supportive strategies to improve the patient surgical care quality. In the literature, numerous studies reported that patients experience significant levels of anxiety and fear before undergoing surgical procedures

\begin{tabular}{|c|c|c|c|}
\hline POPFS Items & Standardized factor loads & $t$ & R2 \\
\hline POPFS Item 1 & 0.76 & 10.63 & 0.58 \\
\hline POPFS Item 2 & 0.71 & 9.78 & 0.51 \\
\hline POPFS Item 3 & 0.65 & 8.73 & 0.43 \\
\hline POPFS Item 4 & 0.77 & 10.83 & 0.59 \\
\hline POPFS Item 5 & 0.85 & 12.73 & 0.73 \\
\hline POPFS Item 6 & 0.71 & 9.83 & 0.51 \\
\hline POPFS Item 7 & 0.69 & 9.43 & 0.48 \\
\hline POPFS Item 8 & 0.75 & 10.51 & 0.56 \\
\hline POPFS Item 9 & 0.64 & 8.54 & 0.41 \\
\hline POPFS Item 10 & 0.63 & 8.40 & 0.40 \\
\hline
\end{tabular}

$R 2=$ squared multiple correlations. Standardized factor loads, t-values, and R2 values of the final model items obtained from confirmatory factor analysis. POPFS: Postoperative pain fear scale

\begin{tabular}{|l|l|l|}
\hline \multicolumn{3}{|l|}{ Table 7. Descriptive statistics of POPFS } \\
\hline POPFS Items & Mean \pm SD $^{*}$ & Median (Min-Max) \\
\hline POPFS Item 1 & $3.82 \pm 3.15$ & $4.00(0.00-10.00)$ \\
\hline POPFS Item 2 & $2.87 \pm 3.11$ & $2.00(0.00-10.00)$ \\
\hline POPFS Item 3 & $2.95 \pm 2.84$ & $2.50(0.00-10.00)$ \\
\hline POPFS Item 4 & $2.98 \pm 2.94$ & $2.00(0.00-10.00)$ \\
\hline POPFS Item 5 & $4.00 \pm 3.57$ & $3.50(0.00-10.00)$ \\
\hline POPFS Item 6 & $2.43 \pm 2.98$ & $1.00(0.00-10.00)$ \\
\hline POPFS Item 7 & $3.58 \pm 3.51$ & $3.00(0.00-10.00)$ \\
\hline POPFS Item 8 & $4.11 \pm 3.48$ & $4.00(0.00-10.00)$ \\
\hline POPFS Item 9 & $3.03 \pm 3.14$ & $2.00(0.00-10.00)$ \\
\hline POPFS Item 10 & $2.64 \pm 3.22$ & $1.00(0.00-10.00)$ \\
\hline Total scale & $3.24 \pm 2.37$ & $3.30(0.00-9.90)$ \\
\hline SD: Stant
\end{tabular}

*SD: Standart deviation descriptive statistics (mean $\pm \mathrm{SD}$, median, $\min$, max), POPFS: Postoperative pain fear scale

$(6,21,22)$. It was also reported that preoperative fear was associated with acute and long-term postoperative pain $(4,23)$. Expecting fear was reported as one of the strong psychological factors that influence the postoperative pain $(7,24)$. Although preoperative pain fear is so important and affects patients' postoperative pain levels, there is not a valid scale to evaluate the fear of postoperative pain.

According to the cross-validation results of the FPQIII scale, the three factors accounted for $58.21 \%$ of the total variance and it was between the expected values of $40-60 \%$ (25). The KMO (expected to be $>0.5$ ) and Bartlett's test scores (expected to be $p<0.05$ ) showed that the sampling was adequate for the factor analysis (26). In the literature, the Cronbach's alpha coefficient value was reported to be $>0.70$ for the internal reliability of a scale $(27,28)$, and in this scale, the total and subscale Cronbach's alpha values were over 0.80 .

Additionally, the present study met the goal of developing the POPFS. In this scale, the correlation 
coefficients between the POPFS total score and all the items were strongly and statistically significant $(p<0.001)$. The existence of a relationship between the items of the scale was related to the validity of the scale. The scale items were to be understood and appropriate to the sample to be applied. These results showed the content validity of the scale.

For the analysis of sampling adequacy, the $\mathrm{KMO}$ index for 150 samples was found as 0.88 to be close to perfect for factor analysis. In the literature, it was reported to be $>0.50$ (26-29). Also for the suitability of the data set the Barlett's test of sphericity showed the sample was coming from a multivariate normal scatter and was found significant with values of $\left(\chi^{2}=807.616, p=0.000\right)$. In the literature, it was reported that Bartlett's sphericity test should be significant $(p<0.05)(26)$. It is also important to test the range sufficiency and partial correlations whether they are small or large. These parameters showed the sampling was appropriate to conduct factor analysis $(25,26,29)$.

Construct validity was proven using EFA and CFA. There are many studies that both factor analyses were conducted on the same data $(30,31)$. In this study, according to the total variance explained, EFA was analyzed for one factor and examination of the screen plot also suggested the factor structure with one factor. The obtained model fit index values through the CFA, including RMSEA, Normed Fit index, Non-normed Fit index, CF, Goodness of-Fit index and Adjusted Goodness-of-Fit index, were close to the acceptable values. In the literature, it is reported that the model fit cutoff indexes are arbitrary and they are affected by many reasons such as estimation methods, sampling fluctuations, small sample size, etc $(32,33)$. For this reason, although one or more fit index values are not highly acceptable, this model may fit the data. In this study, the sample included patients from four different surgical clinics and this may have affected the model fit index values.

The Cronbach's alpha coefficient value of the scale was 0.91 and it met the recommended value for the development of an instrument $(27,28)$. In the literature, the Cronbach's alpha values of the developed Experience of Cognitive Intrusion of Pain scale was 0.94 and of the developed Daily Pain Catastrophizing scale was 0.892 for the total score $(34,35)$. The Cronbach's alpha coefficient values of these pain scales resembled the present study.

With this sufficiently validated scale POPFS, evaluation of the fear of postoperative pain will be possible preoperatively. This instrument will provide health professionals particularly surgery nurses and guidance in knowing the predictors of postoperative pain to make decisions about optimal pain management techniques.
With the evaluation of the pain fear levels of the surgical patients, it is intended to decrease the postoperative pain and anxiety by providing interventions on patient care and medical treatments.

\section{Study Limitations}

One of the limitations of the study is that the study data was collected from four different surgical clinics and this may differ the pain fear levels of the patients. So that, this may affect the model fit index values of this scale. The second limitation is that the scale was about the fear of postoperative pain and it is not possible to test-retest the fear preoperatively. The third limitation is that patients who had previous surgery were also included in the study. However, pain fear levels of patients may be affected by whether they are having surgery for the first time or have had a previous surgery history. Despite these limitations, this study gains a valid and reliable POPFS to the literature. With this scale, it will be able to evaluate the surgical patients' postoperative pain fear during the preoperative period.

\section{Conclusion}

The POPFS is a reliable and valid instrument to measure the fear level of postoperative pain. The scale is appropriate to be used in clinical settings to quickly evaluate the surgical patients' fear level of postoperative pain preoperatively. For future studies, we recommend researchers to use this scale for larger samples and specific surgical patient groups. Further external validation studies are needed to fully appreciate the generalizability of this suggested scale.

\section{Authorship Contributions}

Concept: S.U., F.N.T., Design: S.U., F.N.T., Data Collection or Processing: S.U., Analysis or Interpretation: F.N.T., Literature Search: S.U., F.N.T., Writing: S.U., F.N.T.

Conflict of Interest: No conflict of interest was declared by the authors.

Financial Disclosure: The authors declared that this study received no financial support.

\section{References}

1. Strøm J, Bjerrum MB, Nielsen CV, et al. Anxiety and depression in spine surgery-a systematic integrative review. Spine J 2018;18:1272-85.

2. Alodaibi FA, Fritz JM, Thackeray A, Koppenhaver SL, Hebert JJ. The Fear Avoidance Model predicts short-term pain and disability following lumbar disc surgery. PLoS One 2018;13:e0193566.

3. Londhe SB, Shah RV, Patwardhan M, Doshi AP, Londhe SS, Subhedar K. Understanding the apprehension and concern haunting patients before a total knee arthroplasty. Arthroplasty 2021;3:1-5. 
4. Theunissen M, Peters ML, Schouten EGW, et al. Validation of the surgical fear questionnaire in adult patients waiting for elective surgery. PLoS One 2016;11:e0162737.

5. Burton D, King A, Bartley J, Petrie KJ, Broadbent E. The surgical anxiety questionnaire (SAQ): development and validation. Psychol Health 2019;34:129-46.

6. Cheng JYJ, Wong BWZ, Chin YH, et al. Preoperative concerns of patients undergoing general surgery. Patient Educ Couns 2021;104:1467-73.

7. Wang Y, Liu Z, Chen S, et al. Pre-surgery beliefs about pain and surgery as predictors of acute and chronic post-surgical pain: A prospective cohort study. Int J Surg 2018;52:50-5.

8. Angelini E, Wijk H, Brisby H, Baranto A. Patients' Experiences of Pain Have an Impact on Their Pain Management Attitudes and Strategies. Pain Manag Nurs 2018;19:464-73.

9. Turk DC, Wilson HD. Fear of pain as a prognostic factor in chronic pain: conceptual models, assessment, and treatment implications. Curr Pain Headache Rep 2010;14:88-95.

10. Yüksel A, Çetinkaya F, Karakoyun A. The effect of mindfulnessbased therapy on psychiatric symptoms, psychological wellbeing, and pain beliefs in patients with lumbar disk herniation. Perspect Psychiatr Care 2021;57:335-42.

11. Lewis GN, Rice DA, McNair PJ, Kluger M. Predictors of persistent pain after total knee arthroplasty: a systematic review and meta-analysis. Br J Anaesth 2015;114:551-61.

12. Rajput K, Vadivelu N. Acute Pain Management of Chronic Pain Patients in Ambulatory Surgery Centers. Curr Pain Headache Rep 2021;25:1.

13. McNeil DW, Rainwater AJ 3rd. Development of the Fear of Pain Questionnaire-III. J Behav Med 1998;21:389-410.

14. Simons LE, Sieberg CB, Carpino E, Logan D, Berde C. The Fear of Pain Questionnaire (FOPQ): assessment of pain-related fear among children and adolescents with chronic pain. J Pain 2011;12:677-86.

15. Sullivan MJL, Bishop SR, Pivik J. The pain catastrophizing scale: development and validation. Psychol Assess 1995;7:524-32.

16. Esin N. Data collection methods and tools and reliability and validity of data collection tools. In. Erdoğan S, Nahcivan N, Esin $N$, editors. Nursing research process, application and critic. 3th ed. İstanbul: Nobel Tıp Kitabevleri; 2015. p. 193232.

17. Bağdigen $M$, Karaman Özlü Z. Validation of the Turkish Version of the Surgical Fear Questionnaire. J Perianesth Nurs 2018;33:708-14.

18. Ünver S, Turan FN. Ağrı korkusu ölçeği-III'ün Türkçe geçerlilik ve güvenilirlik çalışması [Turkish validity and reliability study of fear of pain questionnaire-III]. Agri 2018;30:18-27.

19. Altun Öş, Özlü ZK, Kaya M, Olcun M. Does the fear of surgery prevent patients from sleeping? J Anatol Nurs Health Sci 2017;20:260-6.

20. Lawshe $\mathrm{CH}$. A quantitative approach to content validity. Pers Psychol 1975;28:563-75.
21. Masjedi M, Ghorbani M, Managheb I et al. Evaluation of anxiety and fear about anesthesia in adults undergoing surgery under general anesthesia. Acta Anaesthesiol Belg 2017;68:25-9.

22. Mulugeta $H$, Ayana M, Sintayehu M, Dessie G, Zewdu T. Preoperative anxiety and associated factors among adult surgical patients in Debre Markos and Felege Hiwot referral hospitals, Northwest Ethiopia. BMC Anesthesiol 2018;18:155.

23. Lin D, Huang $X$, Wang J, Hao Y, Geng M, Wei C. Effect of preoperative anxiety, depression, and insomnia on acute postoperative pain after non-cardiac surgery. Res Sq April 20 2021. Inpress. https://doi.org/10.21203/rs.3.rs-429163/v1

24. Jayawardane M, Gankanda W, Gunathilake M. Prevalence of pre-operative anxiety and associated factors among a group of women undergoing gynaecological surgeries at a single unit in a tertiary care hospital in Sri Lanka. F1000Res 2021; 10:74.

25. Cokluk O, Sekercioğlu G, Büyüköztürk Ş. Exploratory factor analysis. In: Multivariate statistics for Social Sciences SPSS and Lisrel applications. 5th ed. Ankara: Pegem Yayınevi; 2018. p. 190-240.

26. Field A. Exploratory factor analysis. In: Discovering statistics using SPSS. 5th ed. London: Sage Publications Ltd; 2018. p. 1922-2065.

27. Almanasreh E, Moles R, Chen TF. Evaluation of methods used for estimating content validity. Res Social Adm Pharm 2019;15:214-21.

28. Howard MC. A review of exploratory factor analysis decisions and overview of current practices: What we are doing and how can we improve? Int J Hum-Comput Int 2016;32:51-62.

29. Ekşi H, Kardaş S. Spiritual well-being: Scale development and validation. Spirit Psychol Couns 2017;2:73-88.

30. Saray Kilic H, Tastan S. Development of post hip replacement comfort scale. Appl Nurs Res 2017;38:169-174.

31. Ozturk M, Ersanli E. Development of philanthropy scale. Sci Educ 2018;1:22-33.

32. Hu L, Bentler PM. Fit indices in covariance structure analysis: Sensitivity to underparameterized model misspecification. Psychol Methods 1998;3:424.

33. Schermelleh-Engel K, Moosbrugger H, Müller H. Evaluating the fit of structural equation models: Tests of significance and descriptive goodness-of-fit measures. Methods Psychol Res Online 2003;8:23-74.

34. Attridge N, Crombez G, Van Ryckeghem D, Keogh E, Eccleston C. The Experience of Cognitive Intrusion of Pain: scale development and validation. Pain 2015;156:1978-90.

35. Darnall BD, Sturgeon JA, Cook KF, et al. Development and Validation of a Daily Pain Catastrophizing Scale. J Pain 2017;18:1139-49. 